\title{
Traducción y cultura: reflexiones sobre la dimensión cultural de textos y su importancia para la traducción*
}

\author{
ANGELIKA HENNECKE ${ }^{* *}$ \\ angelika.hennecke@fh koeln.de
}

Recepción: 29 de diciembre de 2014

Aprobación: 10 de febrero de 2015

Forma de citar este artículo: Hennecke, A. (2015). Traducción y cultura: reflexiones sobre la dimensión cultural de textos y su importancia para la traducción. Cuadernos de Lingüística Hispánica, 26, 10-119, Tunja: Uptc.

* Artículo de reflexión.

** Prof. Dr. phil. Angelika Hennecke, es traductora e intérprete con diploma de la Universidad de Leipzig, Alemania, 1988. Doctorado en Ciencias de la Cultura en la Universidad Viadrina de Francfort (Oder), 1998. Profesora titular de Traducción Especializada (español) y Linguística Aplicada de la Universidad de Ciencias Aplicadas de Colonia, Alemania, desde 2006. 


\title{
Resumen
}

En el contexto del cambio cultural en Ciencia de la Traducción en los años 90, se observó la incorporación de factores extralingüísticos en sus estudios. Hoy, la cultura ocupa un lugar generalmente reconocido en la traductología. Sin embargo, quedan abiertas muchas preguntas de índole metodológico y concepcional. Además, el término es usado de un modo general e inflacionario y faltan modelos concretos que permitan operacionalizar la dimensión cultural de los textos para la práctica y la didáctica de la traducción. En este artículo se muestra la compleja interrelación entre lengua, cultura y traducción, a fin de presentar un modelo teórico para describir la dimensión cultural de los textos, que también sea aplicable a la práctica de la traducción. Se parte de una definición semiótica del texto y de la cultura, ya que se considera que la semiótica es la base adecuada para una Ciencia de la Traducción integradora e interdisciplinaria.

Palabras clave: cultura, traducción, semiótica, pragmática, funcionalismo, específica cultural.

\section{Translation and culture: reflections about the culturaldimension of texts and its relevance in translation.}

\begin{abstract}
In the context of cultural change in translation studies in the 1990s, the addition of extra linguistic elements was observed. Nowadays, culture holds a generally renowned position in translation studies. However, many methodological and conceptual questions remain unanswered. Furthermore, this term is used in a general and inflationary manner, and concrete models are lacking, which enable the operationalization of cultural dimensions of texts for the practice and didactics of translation. The complex interrelationships between language, culture and translation are shown in this article, in order to present a theoretical model to describe the cultural dimension of texts, which may be applied in translation as well. Initially, a semiotic definition of text and culture is presented, as semiotics is considered to be the appropriate basis for an integral and interdisciplinary science of translation.
\end{abstract}

Key words: Culture, translation, semiotics, pragmatics, functionalism, cultural specificity. 


\section{Traduction et culture: réflexions sur la dimension culturelle des textes et son importance pour la traduction}

\section{Résumé}

Dans le contexte du changement culturel en Science de la Traduction des années 90, on a observé l'incorporation de facteurs extralinguistiques dans ses études. Aujourd'hui, la culture occupe une place généralement reconnue dans la traductologie. Néanmoins, il y a encore beaucoup de questions d'ordre méthodologique et conceptuel. En plus, le terme est utilisé de manière générale et inflationniste, et il manque des modèles concrets qui permettent d'opérationnaliser la dimension culturelle des textes pour la pratique et la didactique de la traduction. Dans cet article, on montre la complexe interrelation entre langue, culture et traduction, afin de présenter un modèle théorique pour décrire la dimension culturelle des textes, qui soit aussi applicable à la pratique de la traduction. On part d'une définition sémiotique du texte et de la culture, puisque l'on considère que la sémiotique est la base adéquate pour une Science de la Traduction intégratrice et interdisciplinaire.

Mots clés: culture, traduction, sémiotique, pragmatique, fonctionnalisme, specíficité culturelle.

\section{Tradução e cultura: reflexões sobre a dimensão cultural de textos e sua importância para a tradução}

\section{Resumo}

No contexto da mudança cultural em Ciência da Tradução nos anos 90, se observou a incorporação de fatores extralinguísticos em seus estudos. Hoje, a cultura ocupa um lugar geralmente reconhecido nos estudos da tradução. Porém, ficam abertas muitas perguntas de índole metodológica e concepcional. Ademais, o termo é usado de um modo geral e inflacionário e faltam modelos concretos que permitam operacionalizar a dimensão cultural dos textos para a prática e a didática da tradução. Neste artigo se mostra a complexa inter-relação entre língua, cultura e tradução, a fim de apresentar um modelo teórico para descrever a dimensão cultural dos textos, que também seja aplicável à prática da tradução. Parte-se de uma definição semiótica do texto e da cultura, já que se considera que a semiótica é a base adequada para uma Ciência da Tradução integradora e interdisciplinar.

Palavras chave: cultura, tradução, semiótica, pragmática, funcionalismo, específica cultural. 


\section{Introducción}

Desde hace aproximandamente 40 años y en el marco del cambio pragmático, el foco del interés de la Ciencia de la Traducción se ha dirigido más a las cuestiones del uso del lenguaje que a las cuestiones lingüístico-estructurales. Con esto, el texto como tal, el texto-en-función, se situó en el centro de la atención y finalmente se llegó a definir la cultura como unidad de la traducción. En torno a estos cambios se realizó una apertura de la Ciencia de la Traducción hacia una perspectiva interdisciplinaria, la cual incluye explícitamente cuestiones filosóficas, sociológicas, psicológicas, entre otras, en sus estudios. Consecuentemente, después del cambio pragmático, se dio otro cambio de paradigma, el cual terminó en los años 90 en el llamado cultural turn (cambio cultural) (Levefere \& Bassnett-McGuire, 1990). Este cambio de perspectiva es típico para el desarrollo en las últimas décadas. Uno de los motores de este desarrollo fue, sin lugar a duda, la traductología alemana. La afirmación de Snell-Hornby (1988) sobre la traductología alemana, por lo tanto, se puede generalizar para el desarrollo de la ciencia en su totalidad:

What is dominant in the three new basic approaches recently presented in Germany $(. .$.$) is the orientation towards cultural rather than linguistic transfer;$ secondly, they view translation, not as a process of transcoding, but as an act of communication; thirdly, they are all oriented towards the function of the target text (prospective translation) rather than prescriptions of the source text (retrospective translation); fourthly, they view the text as an integral part of the world and not as an isolated specimen of language. These basis similarities are so striking that it is not exaggerated to talk of a new orientation in translation theory. (Snell-Hornby, 1988, p. 43-44).

Podemos constatar entonces que la cultura ha adquirido un lugar generalmente reconocido en la teoría traslativa y que ha inspirado muchos trabajos de investigación y estudios tanto teóricos como prácticos. Sin embargo, quedan abiertas muchas preguntas, sobre todo de índole concepcional y metodológica. Por un lado, el término cultura es utilizado de una manera muy poco específica y al mismo tiempo inflacionaria (véase 
Reinart, 2009, p. 15). Por el otro lado, faltan conceptos y métodos concretos que permitan operacionalizar el concepto de cultura para la práctica y la didáctica de la traducción.

En este artículo se examina en detalle la interrelación entre lengua, cultura y traducción a fin de presentar un modelo que sea aplicable para el proceso traslativo y que sirva para el entendimiento y la transparencia de las decisiones traslatorias. Se parte de una definición y un entendimiento de texto y cultura semióticos, es decir, la semiótica se entiende como la base unificadora. Además, la semiótica es adecuada para ser aplicada para una Ciencia de la traducción moderna e interdisciplinaria. Primero, se trata de describir en un nivel teórico-abstracto la interdependencia entre lengua, texto y cultura, con miras a sacar de esto conclusiones para la actuación traslatoria. Esta actuación traslatoria se entiende como un proceso de transferencia entre distintas culturas. A continuación se definen los elementos concretos que son los responsables del bajage cultural de un texto, o sea, de su carácter específico cultural. Al final se presenta un ejemplo para ilustrar las consideraciones teóricas.

\section{Lengua - Cultura - Texto - Traducción}

Es un lugar común que la lengua es el instrumento más importante de la comunicación y de la reflexión de la realidad cultural. Más problemático parece ser el descubrimiento de la manifestación sistemática de la cultura en los textos producidos por una comunidad linguística y cultural. En el caso de la comunicación entre dos idiomas, como es el caso de la traducción, se añade la dificultad de "trasplantar" el mensaje del texto que se ha de traducir a otra realidad cultural. En otras palabras, o como lo expresa Nord (2014, p. 24), el mensaje del texto tiene que ser referido a la realidad cultural del receptor de la cultura meta, es decir, hay que sobrepasar la llamada "barrera cultural".
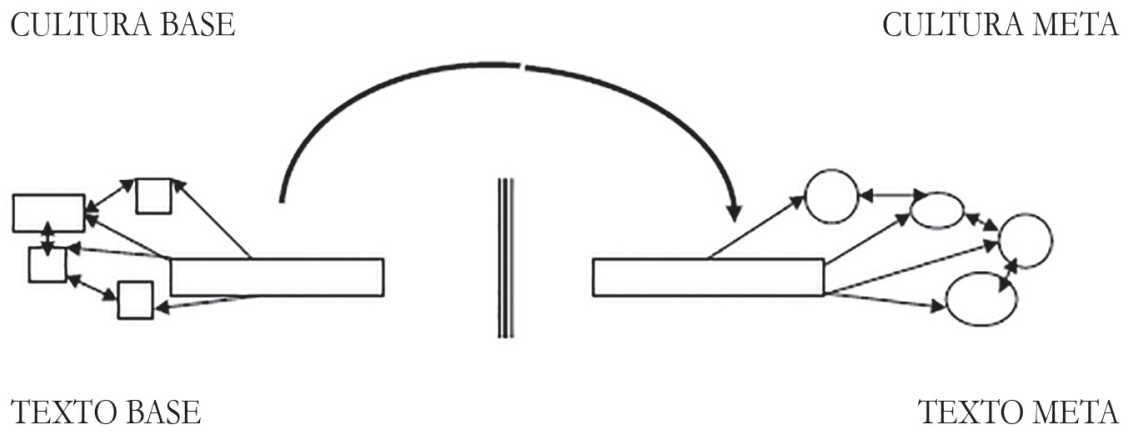

Figura 1. Los conjuntos textuales y la barrera cultural.

Fuente: Nord 2014:24. 
Vermeer (1986, p. 34) considera que la condición para que el 'translatum' se pueda convertir en un elemento integral de la cultura meta, consiste en desatar un fenómeno de sus entramados culturales anteriores de la cultura base e implantarlo en nuevos entramados culturales de la cultura meta. Solamente así se podría lograr lo que llamamos coherencia pragmático-cultural del texto traducido.

Además, la comunicación funciona a partir del uso de códigos convenidos en una comunidad lingüística y cultural contreta; el uso de estos códigos se basa en un consenso cultural. Los interlocutores producen textos de forma intencional. Así interactúan. La producción y recepción de textos puede entonces concebirse como una actuación lingüística en el marco de una situación comunicativa concreta. Una situación comunicativa puede ser una convención socio-cultural. Esto significa que la actuación lingüística está enmarcada en un contexto comunicativo y cultural específicos, es decir, está arraigada en la cultura de los interlocutores.

Sin embargo, la cultura que subyace en los textos, queda manifiesta y visible únicamente en el contraste con otras culturas. La traducción es un caso especial de contraste. El original y su traducción, por lo tanto, son textos especiales que se distinguen de los textos usados en la comunicación monocultural porque se refieren tanto al contexto lingüístico y cultural de la cultura base como de la cultura meta. Con esto, los textos se encuentran en un área de tensión. Uno de los interrogantes más importantes de la interrelación entre lengua, texto, cultura y traducción es, entonces, de qué manera y de qué forma los textos transmiten hechos específicos y no específicos de índole cultural (Gercken, 1999). Además, la pregunta es cómo las normas comunicativas y culturales existentes que subyacen en la estructura base del texto dirigen la textualización en su superficie.

En resumidas cuentas se puede decir que la traducción es prácticamente una simbiosis de las tres categorías lengua, texto y cultura en una situación especial. El acto traslativo, la traducción como proceso es, por consiguiente, una actuación linguiística y social en una situación específica, la cual finalmente encuentra su materialización en el producto - el texto traducido. En el área de la comunicación intercultural, esto significa que el translatum se refiere tanto a aspectos de la cultura de origen como de la cultura meta.

\section{Concepto semiótico de texto y cultura y la coherencia cultural}

Esta nueva perspectiva de la Ciencia de la Traducción tiene que tener naturalmente también consecuencias para la definición y el entendimiento de los conceptos de texto y cultura. Se trata de encontrar una definición de cultura que sea operacionalizable y 
adecuada para el proceso traslativo entendido como proceso de transferencia transcultural. Con la apertura intercultural e interdisciplinaria, el texto adquiere otra dimensión más, la cual quiero describir y denominar como coherencia cultural. Las condiciones para la consecución de la llamada coherencia cultural se distinguen de los factores puramente pragmáticos de la situación comunicativa. La idea de que el texto original está arraigado en la cultura base implica que su traducción, es decir, el texto meta, tiene que encontrar un nuevo enraizamiento en la cultura meta, tiene que ser implantado en la otra cultura, pero no sin dejar de mirar atrás y perder por completo la vinculación con el texto original y la cultura de origen. El resultado de este proceso, si es exitoso, lo llamo el logro de una coherencia cultural.

Al mismo tiempo queda de manifiesto que no se tienen que considerar únicamente los típicos factores extralingüísticos y pragmáticos, como los postula la escuela comunicativopragmática (tiempo, lugar, emitente, receptor, etc.), sino que hay que considerar también la constelación e interrelación de estos factores dentro del modelo cultural de la realidad específica de los receptores del texto meta.

La determinación de un concepto de texto y cultura que permita ser operacionalizado desde el punto de vista traslatorio, constituye la condición metodológica para el descubrimiento de la cultura en los textos, como precondición para su traducción.

No queda duda de que es imposible captar el concepto de cultura en todas sus nociones; tampoco es necesario ni útil tratar de encontrar un denominador común en todas las definiciones existentes (veáse Reinart, 2009, p. 64f).

Sin embargo, queda la pregunta de si una definición referida a la traducción tiene que orientarse primero al aspecto lingüístico o al aspecto cultural, es decir, la pregunta es "si es que la transferencia cultural debe ser un criterio definitivo de cada producto traslativo 0 no"1 (Reinhard, 2009, p. 67). Hay diversas opiniones al respecto, en parte, incluso, opuestas. Si seguimos a Reiss \& Vermeer $(1984$, p. 4) y partimos del hecho de que "la translación no sólo es una transferencia lingüística, sino siempre también una transferencia cultural", entonces, por ende, ambos aspectos - el aspecto linguístico y el aspecto culturaltienen que considerarse en una definición apta para la traducción - independientemente de cómo se defina la relación entre los dos. Es un hecho que la comunicación intercultural puede fracasar tanto en la barrera lingüística como en la cultural (véase Reinart, 2009, p. 69). Por lo tanto, se trata de encontrar un elemento de enlace, una base común, para una definición que considere ambos aspectos de manera igual. En mi opinión, esta base, este

1 Todas las traducciones de las fuentes en alemán son hechas por la autora. 
denominador común, solo lo puede aportar la semiótica, por lo cual quiero presentar una definición semiótica de texto y cultura a continuación. una definición muy frecuentemente usada y citada, también en la Ciencia de la Traducción, es la de Goodenough. Pone de relieve el aspecto social de determinadas formas de comportamiento. Esto implica que la cultura no existe independientemente del sujeto:

As I see it, a society's culture consists of whatever it is one has to know or believe in order to operate in a manner acceptable to its members, and do so in any role that they accept for any one of themselves. Culture, being what people have to learn as distinct from their biological heritage, (...) it is not a material phenomenon; it does not consist of things, people, behavior, or emotions. It is rather an organization of these things. It is the form of things that people have in mind, their models of perceiving, recording, and otherwise interpreting them. (Goodenough, 1964, p. 36).

En el mismo sentido apunta la conocida definición de Hofstede quien entiende la cultura como una programación social y cultural que uno aprende durante su socialización y su vida. Habla de determinados patrones del pensamiento, del sentimiento y de la actuación en un sentido de "software of the mind". (Hofstede 1991).

Estas definiciones tienen una orientación hacia comportamiento y al sujeto, y en mi opinión, no son adecuadas o aptas para reflejar de manera profunda la interrelación entre lengua, cultura y traducción. Tampoco corresponden al carácter simbólico de la lengua y de la cultura, es decir, no reflejan de manera satisfactoria la función de lengua y cultura.

Si se hace énfasis en el hecho de que toda clase de comunicación se realiza a partir del uso de distintos códigos - códigos de diferentes sistemas de signos-, entonces esto nos lleva a una concepción semiótica de texto y cultura y, por ende, del proceso traslativo.

Con esta interpretación, es decir, con la concepción de que la cultura es leíble e interpretable como un texto a partir de códigos válidos (Geertz, 1983), se desmistifica el concepto de cultura y texto. Con una perspectiva semiótica también se logra superar la arriba mencionada controversia entre un entendimiento de la traslación como transferencia lingüística o cultural, porque la base unificadora es la postulación de que tanto la lengua, como el texto y la cultura son sistemas de signos, para cuyo entendimiento se necesita el conocimiento de códigos determinados y culturalmente convencionalizados. Al mismo tiempo se destaca el carácter funcional de estos sistemas de signos porque son instrumentos con una función. Adicionalmente, esta concepción semiótica también abarca el concepto de conocimientos, porque se necesita conocer el significado de los respectivos códigos para poder descifrar el sentido de los signos. Además, es importante subrayar que 
así se añade al concepto de la traducción otra dimensión más, ya que los códigos no tienen que ser exclusivamente de carácter verbal. También se consideran códigos de naturaleza extra lingüística, como por ejemplo, imágenes como partes integrantes de un texto. Por el hecho de que estos códigos se encuentran en un proceso de continua elaboración y modificación, la cultura, además, no se concibe como un sistema acabado y estático, sino como un sistema dinámico y variable.

En conclusión, se puede decir que el texto se entiende como parte de la cultura en la que es producido y comunicado, y que se destaca su carácter de signo -además de su dependencia de los factores pragmático-situativos-. Sobre esta base semiótica se puede lograr una vinculación de los dos conceptos texto y cultura:

Si un objeto es un texto, depende de tres condiciones:

1. Tiene que ser un artefacto, es decir, resultado de un comportamiento intencional.

2. Tiene que ser un instrumento, es decir, tiene que haber una cultura en la que rige una convención que le de -al menos una-función.

3. Tiene que ser codificado, es decir, tiene que haber una cultura en la que existe un código que le de uno o más significados. (Posner, 1991, p. 46).

La cultura se entiende como un sistema y un modelo estructurado de la interpretación de la realidad. Posner define las culturas como sistemas de signos: "Culturas son sistemas de signos" (Posner, 1991, p. 39).

Un sistema de signos culturales comprende usuarios individuales y colectivos de los signos, que producen textos en los cuales se formulan mensajes mediante determinados códigos convencionales, los que les permiten a los usuarios solucionar los problemas de su vida cotidiana. (ibd. 53-54).

Los productores y receptores de textos, los traductores y otros son portadores de cultura y usuarios de signos. La cultura mental, entonces, no es otra cosa que un sistema de convenciones semióticas, es decir, de convenciones de signos, que regulan el comportamiento social de los usuarios de signos y las funciones y significados de sus artefactos. Esta perspectiva también supera la separación de las tres dimensiones de la cultura, o sea, de su dimensión material, social y mental:

Si una sociedad es un conjunto de usuarios de signos, una civilización, un conjunto de textos y una mentalidad un conjunto de códigos; entonces estas tres áreas están necesariamente vinculadas, porque los usuarios de signos necesitan los códigos para el entendimientos de los textos. (ibd. 53). 


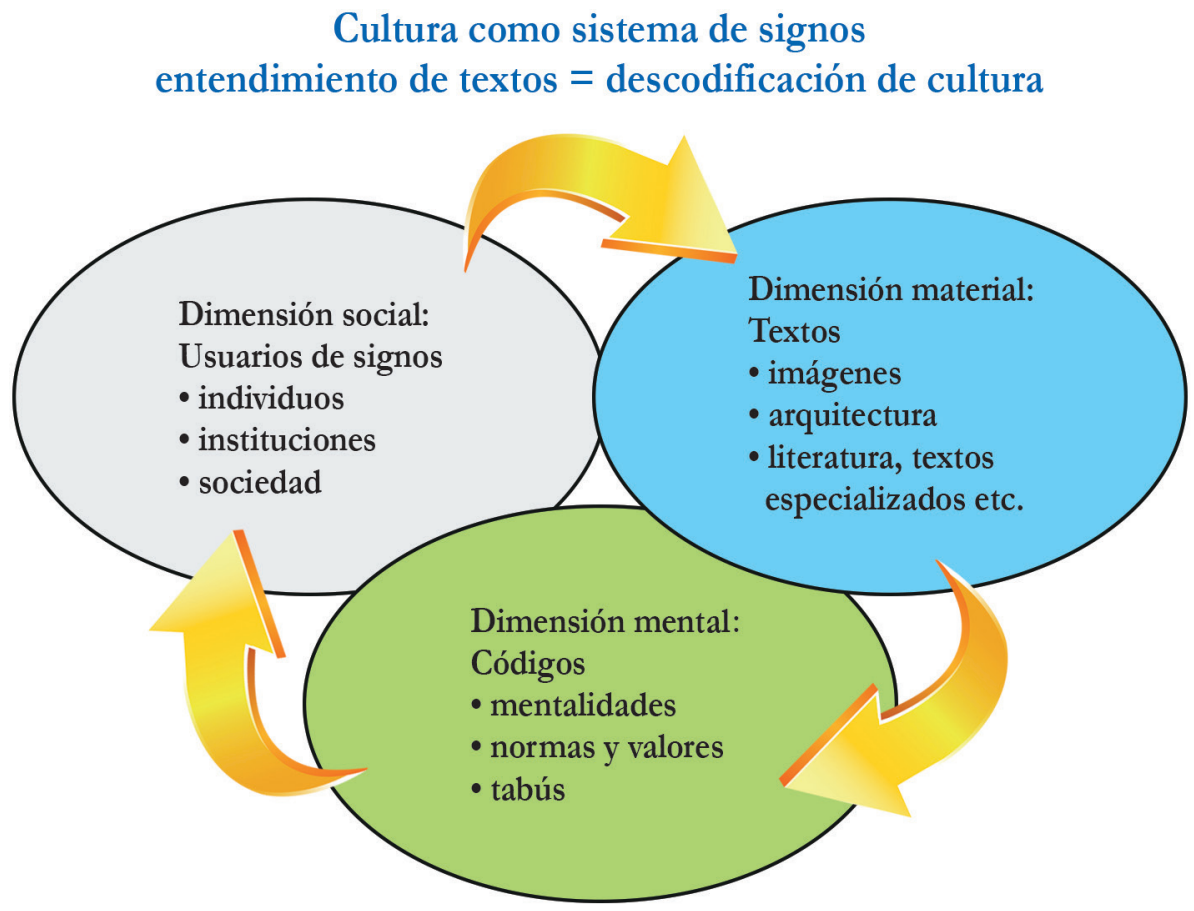

Figura 2: Cultura como sistema de signos

Entonces, el entendimiento de textos puede concebirse como la descodificación de cultura. Si el mensaje de un texto llega al receptor en la forma pretendida, depende por un lado de su encodificación por parte del productor y de su descodificación por parte del receptor. Para esto hay que recurrir a conocimientos linguísticos y textuales y a conocimientos extralingüísticos culturalmente específicos.

El texto como signo lingüístico complejo está enmarcado en varias relaciones. Está situado primero en el co-texto, es decir, en sí mismo, y además en una situación, es decir, en el contexto. El mensaje del texto, que el traductor debe primero reconstruir e interpetar, con el fin de transferirlo después de manera adecuada a la lengua meta, recibe influencia de una serie de factores que en su conjunto y en sus interrelaciones defino como una "compleja presuposición situativa" (alemán: komplexe Voraussetzungssituation). El texto meta (el translatum) tiene que transmitir el mensaje del texto base, y el traductor tiene que adaptarlo a las condiciones del receptor de la cultura meta de manera que logre el mismo efecto y que se dé una coherencia cultural.

El texto es un sistema estructurado en una situación compleja, para el cual se da una coherencia en tres niveles (véase figura 3). Sin embargo, estos tres niveles están 
estrechamente vinculados y entrelazados. El concepto semiótico del texto - aquí utilizadoimplica al mismo tiempo que las tres dimensiones de un signo -su dimensión semántica, sintáctica y pragmática- estén relacionadas y no se puedan contemplar de manera aislada. Por ejemplo, una decisión que el traductor tome a nivel semántico de un texto, tiene al mismo tiempo consecuencias pragmáticas o viceversa. De esto se deduce que la coherencia cultural de un texto no es el resultado de una acción independiente, sino que depende, a la vez, de la realización de la coherencia semántica y pragmática.

NIVELES DEL SIGNIFICADO DEL TEXTO

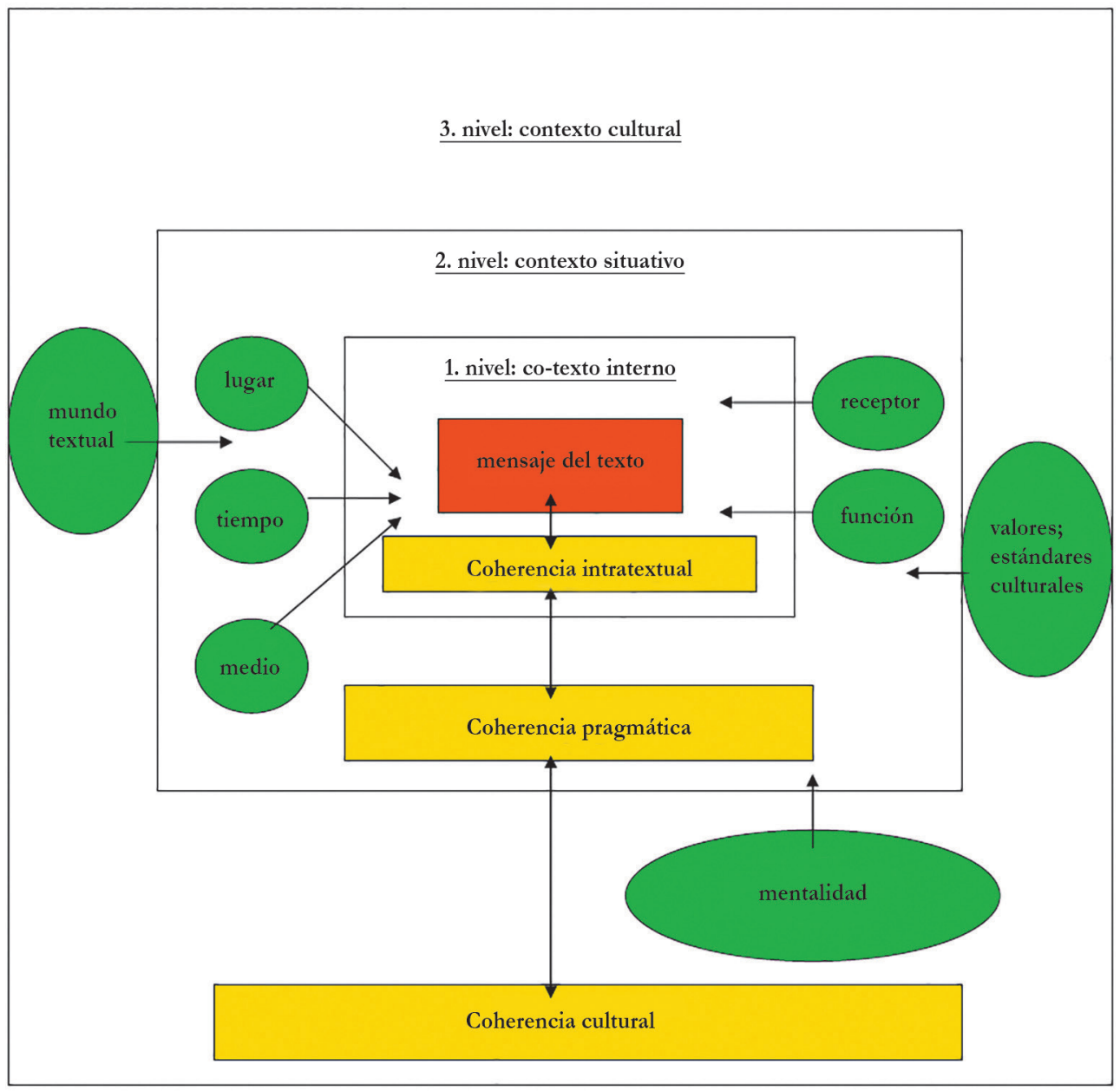

Figura 3: Los niveles de coherencia de un texto 
Los tres niveles de coherencia de un texto que acabé de presentar en un modelo, corresponden prácticamente a las tres dimensiones de la cultura: el primer nivel es el texto en sí mismo, es decir, la dimensión material. En el segundo nivel, el receptor juega un papel decisivo, y junto con los demás factores pragmático-situativos corresponde a la dimensión social. Finalmente, el tercer nivel, la cultura como sistema de signos, corresponde a la dimensión mental.

Como ya se mencionó, los factores de la compleja presuposición situativa y de la cultura como sistema de signos son variables y cambian. Esto implica que una traducción solamente puede ser "correcta" o "adecuada" de forma relativa, es decir, siempre y únicamente con respecto a y en dependencia de la situación comunicativa y cultural concreta. Los signos -y entonces también un texto como signo complejo- no tienen de por sí un significado, sino los significados se constituyen únicamente en su uso y son el resultado de la descodificación e interpretación por el usuario, para lo cual este recurre a sus conocimientos universales, individuales y culturales.

Ahora, se puede operacionalizar para el proceso traslativo: los signos no tienen un significado de por sí; además los significados no son entidades dadas y fijas, sino variables y dinámicas. La determinación de las características semánticas indefinidas y abiertas de los signos utilizados en un texto se efectúa a través de su referencia al marco cultural (= cultura como sistema de signos). Esto quiere decir que el marco cultural es prácticamente la superficie de proyección para el texto y sus signos. Pero este sistema como un todo también es variable y cambia con el tiempo. Consecuentemente, una traducción solo puede ser adecuada de manera relativa, en el marco de la compleja situación presupuesta: "Los signos no funcionan en la comunicación a pesar de, sino mas bien por $^{2}$ su vaguedad e indeterminación” (Abel, 2000, p. 90). Sus valencias semánticas y pragmáticas abiertas permiten su conexión con diferentes situaciones e interlocutores. Los significados entonces no son estructuras o lugares fijos, sino tienen que ser concebidos como funciones de signos variables y dinámicos.

\section{Elementos culturales específicos}

Nos damos cuenta de una diferencia cultural siempre cuando en la situación de la traducción el significado de una expresión, de una frase o de un texto completo nos parece difuso, cuestionable o completamente inentendible. Entonces, heurísticamente, se buscan primero estos elementos textuales, que prácticamente son la manifestación concreta del sistema cultural holístico en la superficie del texto. Interactúan dos niveles: el nivel de

2 Resaltado por la autora. 
las manifestaciones lingüísticas concretas (los textos o elementos textuales) y el nivel del modelo de la realidad, al que se tienen que referir estos elementos a fin de descodificarlos. La mutua referencia entre ambos niveles se conduce y se dirige esencialmente gracias a los conocimientos del receptor del texto.

En la literatura científica se encuentran diferentes términos para denominar estos elementos específicos con marca cultural. Las definiciones y determinaciones de lo que hay que entender bajo la culturalidad específica de un texto dependen mucho del autor así como de su intención y su interés investigativo.

Frecuentemente se encuentran las denominaciones "elementos culturales específicos" (specific cultural items), como en la definición siguiente:

SCIs [specific cultural items] are those textually actualized items whose function and intertextual load in a ST [source text] cause a translation problem due to either the non-existence of the referred item in the target system or due to its different intertextual and cultural implications. (Franco Aixelá, 1995:114).

Hansen (1996, p. 63) utiliza el término "específicos culturales", "culturema", "elementos vinculados a la cultura" para todos aquellos hechos y fenómenos de una comunidad lingüística que provocan un determinado entendimiento y comportamiento en una situación concreta. Esta definición implica que los términos culturales no se definen de una vez para siempre, sino que pueden cambiar. Además incluye también elementos extra verbales.

Gercken (1999, p. 113 ff.) distingue entre dos tipos de referencias culturales en textos que cobran importancia en una perspectiva contrastiva (como en el caso de la traducción): Referencias culturales explícitas, que son realizadas a través de léxico o nombres propios con un contenido semántico culturalmente específico. También pueden existir enunciaciones verbales explíticas a nivel de una frase o de un texto. Referencias culturales implícitas, que se manifiestan a nivel de una frase 0 de un texto, a través de relaciones textuales que no tienen una marcación explícita. Esta forma de expresar significados culturales muchas veces presupone conocimientos extratextuales de parte del receptor y no tienen un bagaje cultural per se. Su carácter cultural específico se da únicamente a través de su proyección al modelo de realidad de una comunidad lingüística y cultural.

Pero no solamente elementos lingüísticos aislados, sino los tipos de textos como tales pueden tener formas culturalmente específicas. La ciencia ha hecho distintos aportes en este sentido en los últimos años. Sin embargo, el estudio de las diferencias culturales 
de clases y tipos de textos no se puede considerar por terminado. Pueden diferenciarse el diseño textual y las normas de la textualización, incluso, su diseño gráfico. La suposición ampliamente compartida de que la específica cultural sería primordialmente una cuestión de los textos literarios o de ficción, se pone en duda cada vez más por los avances en la investigación de las lenguas especializadas, que nos brindan indicios serios para un uso culturalmente específico de los términos técnicos y especializados.

\section{Ejemplo: Referencias culturales implícitas a nivel de frase}

Al comienzo del nuevo milenio, en Colombia se vio en la prensa y en la televisión el siguiente eslogan:

\section{"El nuevo milenio. Todos en casa."}

En una clase de traducción les presenté este eslogan a mis estudiantes alemanes, a fin de demostrarles el problema de los conocimientos presupuestos y su importancia para la reconstrucción del mensaje de un texto y, por ende, para la traducción. Los estudiantes optaban por una traducción literal, palabra por palabra, ya que este texto no presenta elementos culturales específicos a primera vista. Podemos encontrar equivalentes léxicos exactos en un dicccionario para cada palabra. Sin embargo, la traducción al alemán no tenía sentido:

\section{"Das neue Millenium. Alle sind zu Hause."}

El sentido de este texto solamente se da, si se refiere el contenido semántico a la realidad específica colombiana, es decir, si el texto como tal es referido al marco del sistema cultural. Se trata aquí de una referencia cultural implícita a nivel de frase/texto, que no está marcada semánticamente. El mensaje del texto solamente es reconstruible e interpretable a partir de la referencia al sistema cultural y a base de la incorporación de elementos extra textuales en la reconstrucción del sentido.

Para los colombianos, este mensaje era muy claro y se entendía inmediatamente, ya que al leer este eslogan se activaban los elementos presupuestos de conocimientos sobre la realidad en el país en estos años. Durante el proceso de paz entre el Gobierno del entonces presidente Pastrana y las FARC, los secuestros dominaban la vida de los colombianos y dificultaban no solamente la vida de cada uno, sino también ponían en peligro el proceso de paz.

Al explicar todo este trasfondo a mis estudiantes alemanes, ellos llegaron a entender que la función del eslogan no era una función descriptiva o referencial, lo que insinúa la construcción sintáctica: es una oración enunciativa. Sin embargo, al referir el texto al marco socio-cultural de Colombia al principio del nuevo milenio, se da una función 
apelativa: mas bien debería ser una oración exclamativa (pero no lo es en el texto original). Para una posible traducción al alemán encontramos propuestas como: "Schlu $\beta$ mit den Entführungen im neuen Millenium!" "Alle haben das Recht, zu Hause zu sein. Hört auf mit den Entfïbrungen!"3

Este es un buen ejemplo tanto de la existencia de referencias implícitas a nivel de texto que no están de ninguna manera marcadas semánticamente y cuyo sentido solamente se despliega al referir el mensaje semántico al modelo cultural - la cultura como signo. Es también un ejemplo de que no podemos explicar la reconstrucción de sentido en un texto con la categoría de una equivalencia estructural. El sentido del texto únicamente se puede reconstruir al establecer la coherencia cultural.

\section{Conclusiones}

Como se ha demostrado, no todas las preguntas relacionadas con el fenómeno de la cultura y su importancia para la traducción han sido resueltas desde el enfoque pragmático-cultural en la Ciencia de la Traducción, sobre todo en el terreno metodológico. El problema de la manifestaciónn cultural en los textos puede examinarse desde diferentes perspectivas y a base de diferentes modelos - desde casos específicos contrastivos entre dos idiomas hasta una concepción holística. Según el interés investigativo, todos estos accesos tienen su justificación y no se excluyen, sino se complementan mutuamente.

En este artículo se postula una definición y una perspectiva semióticas para el texto, la cultura y, por consiguiente, el proceso traslativo, porque la semiótica se considera la base unificadora para incorporar todos los aspectos relevantes. Sobre esta base se definió la dimensión de la coherencia cultural de textos, la cual sobrepasa la coherencia pragmáticosituativa y considera la cultura como un sistema de signos que sirve como superficie de proyección para el texto por traducir.

La vaguedad semántica de los signos puede determinarse por su referencia al modelo cultural existente. En el caso de la traducción, el traductor se encuentra en un terreno de tensión, ya que no solamente tiene que considerar el modelo cultural de los destinatarios del texto meta, sino también tiene que respetar la vinculación del texto original con la cultura base y así garantizar las coherencias inter- e intratextuales del translatum.

La manifestación concreta de la cultura en la superficie de los textos se realiza a través de distintos y diferentes elementos, tanto léxicos como no léxicos. Para la traducción de estas referencias culturales existen varias propuestas de procedimientos y estrategias.

3 ¡Terminen los secuestros en el nuevo mileno! Todos tienen el derecho de estar en casa. ¡Pongan fin a los secuestros! 
Según Nord (2007, p. 301), se puede distinguir entre dos tipos básicos generales: la traducción documento o la traducción instrumento. La decisión metodológica del traductor depende de una serie de distintos factores de la situación comunicativa concreta. Los factores que juegan un papel son el encargo de traducción, el destinatario, el medio, el tiempo, la función pretendida del translatum y otros.

Esto significa que una traducción solamente puede ser adecuada e idónea en relación con esta situación concreta. Para la didáctica y la formación de futuros traductores esto implica la necesidad del entrenamiento de la competencia cultural, aparte de las competencias lingüística, traslatoria y técnica. En primer lugar, se trata de sensibilizar sobre esta problemática y hacer transparentes las decisiones traslatorias. No se trata de presentar soluciones acabadas y únicas, sino de concientizar para el cambio de perspectiva.

\section{Referencias bibliográficas}

Abel, G. (2000). Übersetzung als Interpretation. En: Büttemeyer, Wilhelm \& Hans Jörg Sandkühler (ed.): Übersetzung: Sprache und Interpretation. Francfort etc.: Peter Lang, p. 85-102.

Franco Aixelá, J. (1995). Specific Cultural Items and their Translation. En: Jansen, P. (ed.): Translation and the Manipulation of Discourse. Leuven: CETRA - The Leuven Research Center for Translation, Communication and Cultures, p. 109-123.

Geertz, C. (1983). Dichte Beschreibung. Beiträge zum Verstehen kultureller Systeme. Francfort: Suhrkamp Verlag.

Gercken, J. (1999) Kultur, Sprache und Text als Aspekte von Original und Übersetzung. Francfort etc.: Peter Lang.

Goodenough, W. H. (1964). Cultural anthropology and linguistics. En: Hymes, Dell (1994) (ed.): Language in Culture and Society. Nueva York: Harper \& Row; J. Weatherhill, p. 36-39.

Hofstede, G. (1991). Cultures and Organizations. Software oft the mind: Intercultural Cooperation and ist Importance for Survival. Londres: McGraw-Hill.

Levefere, A., \& Bassnett-McGuire, S. (1990). Introduction: Proust's Grandmother and the Thousand and One Nights: The 'Cultural Turn' in Translation Studies. Translation, History and Culture. Londres: Pinter.

Nord, C. (2007). Übersetzungstypen - Übersetzungsverfahren: Ein paar neue Gedanken zu einem uralten Thema. En: Wotjak, G. (ed.): Quo vadis Translatologie? Ein halbes Jabrhundert 
universitäre Ausbildung von Dolmetschern und Übersetzern in Leipzig. Berlìn: Frank \& Timme, p. 293-310.

Nord, C. (2014). Hürden-Sprünge. Ein Plädoyer für mehr Mut beim Übersetzen. Berlín: BDÜFachverlag.

Posner, R. (1991). Kultur als Zeichensystem. Zur semiotischen Explikation kulturwissenschaftlicher Grundbegriffe. En: Assmann, A., \& Dietrich Harth (ed.): Kultur als Lebenswelt und Monument. Francfort: Fischer, p. 37-74.

Reinart, S. (2009). Kulturspezifik in der Fachübersetzung. Berlín: Frank \& Timme.

Reiß, K., \& Vermeer, H. (1984). Grundlegung einer allgemeinen Translationstheorie. Tubinga: Max Niemeyer Verlag.

Snell-Hornby, M. (1988). Translation Studies - An Integrated Approach. Amsterdam: John Benjamins.

Vermeer, H. (1986). Übersetzen als kultureller Transfer. En: Snell-Hornby, M. (ed.): Übersetzungwissenschaft - eine Neuorientierung. Zur Integration von Theorie und Praxis. Tubinga: Francke, pp. 30-53. 